\title{
Potent $\alpha$-glucosidase inhibitors from the lichen Cladonia species from Sri Lanka
}

\author{
Veranja Karunaratne', Vinitha M. Thadhani2 ${ }^{*}$, Shamsun Nahar Khan ${ }^{3}$ and M. Iqbal Choudhary ${ }^{3,4}$ \\ ${ }^{I}$ Department of Chemistry, Faculty of Science, University of Peradeniya, Peradeniya. \\ ${ }^{2}$ Department of Chemistry, Faculty of Applied Sciences, University of Sri Jayewardenepura, Gangodawila, Nugegoda. \\ ${ }^{3}$ H.E.J. Research Institute of Chemistry, International Center for Chemical and Biological Sciences, University of Karachi, Karachi-75270, Pakistan. \\ ${ }^{4}$ Department of Chemistry, School of Sciences. King Saud University, Riyadh-11451, Saudi Arabia.
}

Revised: 09 November 2013; Accepted: 28 November 2013

\begin{abstract}
The discovery of $\alpha$-glucosidase inhibitors has been actively pursued with the aim to develop therapeutics for the treatment of diabetes and other carbohydrate-mediated diseases. This study focused on the lichen Cladonia sp., which yielded three potent $\alpha$-glucosidase inhibitors, namely zeorin (1), methyl $\beta$-orcinolcarboxylate (2) and methylorsellinate (3) with several fold higher inhibitory activities than those of acarbose, an antidiabetic drug used to manage type II diabetes mellitus and the standard, 1-deoxynojirimycin. Atranorin (4) and lobaric acid (5), the other two metabolites isolated from the lichen did not show any $\alpha$-glucosidase inhibitory potential. All compounds were identified on the basis of one dimentional (1D) and two dimentional (2D) NMR spectral data and with comparison to reported data.
\end{abstract}

Keywords: $\alpha$-Glucosidase inhibitory activity, diabetes type II, lichen metabolites, methyl $\beta$-orcinolcarboxylate, methylorsellinate, zeorin.

\section{INTRODUCTION}

Diabetes mellitus (DM) is the most common endocrine disease affecting about 173 million people $(2.8 \%)$ worldwide and is expected to reach $4.4 \%$ (366 million) by 2030 (Elya et al., 2012). The prevalence estimates of DM are high for all Asian countries and are expected to double in the next two decades. Sri Lanka is also expected to face a high burden of DM in the coming years (Katulanda et al., 2008).

This situation has prompted numerous efforts to investigate for new therapeutic agents to stem the progress of diabetes. One of the strategies in the management of $\mathrm{DM}$, in particular non-insulin-dependent DM, is to inhibit the absorption of carbohydrates. Intestinal $\alpha$-glucosidases are involved in the final step of the carbohydrate digestion, converting them into monosaccharides. Hence, the inhibitors of $\alpha$-glucosidases retard the liberation of D-glucose, resulting in the suppression of postprandial hyperglycemia and therefore, are used as an effective treatment of type II diabetes and obesity (Raskin et al., 2007).

$\alpha$-Glucosidases are also effective in lowering the insulin release, which leads to the lowering of plasma lipids. The current interest in $\alpha$-glucosidase inhibitors has been extended to a diverse range of diseases including lysosomal storage disorders, cancer and AIDS. In addition, $\alpha$-glucosidase inhibitors have also been used as antiobesity drugs, fungistatic compounds, insect antifeedants, antivirals and immune modulators (Thadhani et al., 2011 b)

Natural products possess great structural diversity and are an attractive source to investigate for finding novel chemotypes to control hyperglycaemia. One of the most potent hyperglycaemic active plants native to Sri Lanka and India is Salacia reticulata Wight (Kotalahimbutu: Sinhalease). Although its rich chemistry of organic-soluble extracts was investigated in Sri Lanka (Gunatilaka et al., 1993; Tezuka et al., 1993; Tezuka et al., 1994; Dhanabalasingham et al., 1996) the potent $\alpha$-glucosidase activity of the aqueous extract was reported by a group of Japanese researchers (Yoshikawa et al., 
1997). In addition, various plant metabolites such as flavanoids, alkaloids, terpenoids, saponins, anthocyanins, curcumnoids, phenolic compounds etc., have shown potent $\alpha$-glucosidase inhibitory activity (Kumar et al., 2011). The saponin rich Sri Lankan plant Cyclea burmanni Arn. ex Wight remains unexplored for its antidiabetic activity (Bandara et al., 1989). More than ca. 1200 plant species have been recorded to be used empirically worldwide for their alleged hypoglycaemic activity (Tundis et al., 2010). Higher plants still continue to be a rich source for compounds with potential antidiabetic activity. Besides, lichens have been largely unexplored for metabolites possessing antidiabetic activity. Interestingly, tropical lichens, particularly those from Sri Lanka, continue to yield a wide variety of biologically active compounds, and also serves as a rich source of new lichen species (Orange et al., 2001; Karunaratne et al., 2005; Choudhary et al., 2009; Williams et al., 2011; Thadhani et al., 2011a \& 2012; Jayalal et al., 2012). In the present study, the focus was on the constituents from the lichen Cladonia sp. of Sri Lankan origin with potent $\alpha$-glucosidase inhibitory activity (Thadhani et al., 2011b). Cladonia sp. used in this study belongs to the family Cladoniaceae, which is a large family with over 70 known species (Ahti et al., 1993). Northern Native American people used Cladonia sp. in medicinal teas to treat colds, fevers, jaundice, and as poultice to relieve the ache of arthritic joints, for the treatment of convulsions, coughs, and tuberculosis (Brown, 2001).

\section{METHODS AND MATERIALS}

Cladonia sp. specimens were collected from the rocks of Labukella, Central Province, Sri Lanka. A voucher specimen was identified and deposited at the National Herbarium, Peradeniya (pdnA 3410 4). The lichen specimens were cleaned, washed and air-dried at room temperature, and sequentially extracted into $\mathrm{CH}_{2} \mathrm{Cl}_{2}$ and $\mathrm{MeOH}$. Silica gel column chromatography of the $\mathrm{CH}_{2} \mathrm{Cl}_{2}$ extract of the lichen yielded zeorin (1) $(0.52 \%)$, methyl $\beta$-orcinolcarboxylate (2) (0.08\%), atranorin (4) (0.29\%), and the $\mathrm{MeOH}$ extract afforded methylorsellinate (3), $(0.02 \%)$ and the depsidone lobaric acid (5) $(0.04 \%)$ on the dry weight basis of the lichen. All compounds were identified on the basis of 1D and 2D NMR spectral data and comparison with the reported spectral data (Huneck \& Yoshimura, 1996).

The $\alpha$-glucosidase inhibition of theisolated compounds (5 $\mu \mathrm{L}, 1 \mathrm{mM})$ was measured spectrophotometrically at $\mathrm{pH} \quad 6.9$ and at $37{ }^{\circ} \mathrm{C}$ using $p$-nitrophenyl- $\alpha$-Dglycolpyranoside (PNP-G) $(0.5 \mu \mathrm{M})$ as the substrate and 250 units/ $\mathrm{mL}$ of enzyme, in $50 \mathrm{mM}$ sodium phosphate buffer containing $100 \mathrm{mM} \mathrm{NaCl}$, acarbose $(0.78 \mathrm{mM})$ and 1-deoxynojirimycin $(0.425 \mathrm{mM})$ were used as positive controls (Oki et al., 2000). The increments in absorption due to the hydrolysis of PNP-G by $\alpha$-glucosidase were monitored continuously with a spectrophotometer at $\lambda 400 \mathrm{~nm}$. All reactions were performed in triplicate in

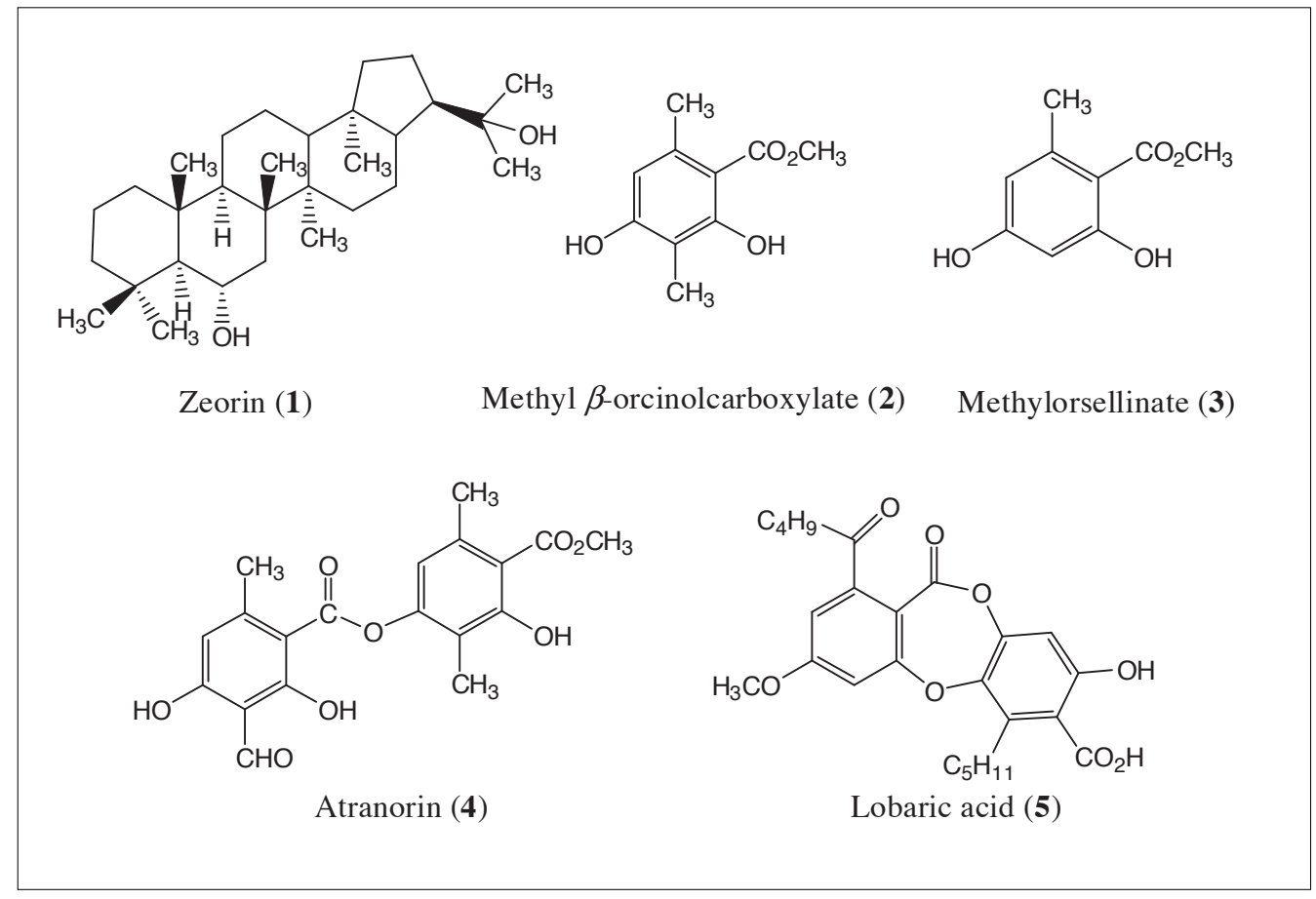

Figure 1: Structures of compounds (1) - (5) isolated from Cladonia sp. 
96-well microplates. The results were processed using ELISA (multiple reader Spectra Max Plus -384, and 3400 Molecular Devices, CA, USA). The $\mathrm{IC}_{50}$ values of the compounds were calculated using EZ-Fit Enzyme kinetics software programme (Perrella Scientific Inc., Amherst, USA).

\section{RESULTS AND DISCUSSION}

From the isolated compounds 1 - 5, triterpenoid zeorin (1) showed the highest $\alpha$-glucosidase inhibitory activity with an $\mathrm{IC}_{50}$ value of $100.0 \pm 0.3 \mu \mathrm{M}$, which is seven times lower than that of acarbose, $\left(\mathrm{IC}_{50}=700.0 \pm\right.$ $10.4 \mu \mathrm{M}$ ), a widely prescribed drug in the management of type II diabetes, and four fold more active compared to the potent $\alpha$-glucosidase inhibitor, 1 - deoxynojirimycin $\left(\mathrm{IC}_{50}=425.0 \pm 8.9 \mu \mathrm{M}\right)$. The two phenolic compounds, methyl $\beta$ - orcinolcarboxylate (2) $\left(\mathrm{IC}_{50}=140.0 \pm 0.6\right.$ $\mu \mathrm{M})$ and methylorsellinate $(3)\left(\mathrm{IC}_{50}=165.0 \pm 1.2 \mu \mathrm{M}\right)$ also exhibited 4 - 5 fold higher activity than acarbose. Importantly, neither zeorin (1) nor methylorsellinate (3) showed any cytotoxicity in the brine shrimp lethality assay (Thadhani et al., 2012), thus highlighting its potential use as a drug candidate. However, methyl $\beta$ orcinolcarboxylate (2) showed moderate cytotoxicity with a $\mathrm{LD}_{50}$ value of $17.07 \mu \mathrm{g} / \mathrm{mL}$ as compared to the standard etoposide $\left(\mathrm{LD}_{50}=7.43 \mu \mathrm{g} / \mathrm{mL}\right)$. It is noteworthy that kotanalol and salacinol, the two well-known $\alpha$-glucosidase inhibitors isolated from $S$. reticulata, showed only a maximum of $1-1.5$ fold $\alpha$-glucosidase inhibitory activity compared to the standard drug acarbose (Yoshikawa et al., 1997). However, the other two compounds isolated from the lichen, namely atranorin (4) and lobaric acid (5) showed no $\alpha$-glucosidase inhibitory properties.

Methylorsellinate or 2,4-dihydroxy-6-methylbenzoate (3) has been reported from various lichens such as Parmotrema grayana, Roccella montagnei and Pseudocyphellaria crocata. Methyl $\beta$-orcinolcarboxylate or 2,4-dihydroxy-3,6-dimethyl benzoate (2) is a common lichen metabolite reported from Stereocaulon alpinum Laur., etc. Zeorin or 6, 22-hopanediol (1) is a common constituent of various lichens, i.e. Heterodermia, Anaptychia, Lecanora, Parmelia, Nephroma and Placodium sp. Although zeorin (1) is one of the most common lichen specific metabolites, no bioactivities of this compound have been reported before to the best of our knowledge. Various bioactivities of methyl $\beta$ orcinolcarboxylate (2) have been reported including anticancer activities (Huneck, 1999), while methylorsellinate (3) exhibits antibacterial and antifungal activities (Thadhani et al., 2012). Significantly, this is the first report on the $\alpha$-glucosidase inhibitory activity of lichen compounds.

\section{REFERENCES}

1. Ahti T., Stenroos S. \& Filho L.X. (1993). The lichen family Cladoniaceae in Paraiba, Pernambuco and Sergipe, Northeast Brazil. Tropical Bryology 7: 55 - 70.

2. Bandara B.M.R., Jayasinghe L., Karunaratne V., Wannigama G.P., Kraus W., Bokel M. \& Sotheeswaran S. (1989). Diploclisin, a bidesmosidic triterpenoid saponins from Diploclisia glaucescens. Phytochemistry 28: 2783 2785.

3. Brown D. (2001). Encyclopedia of Herbs and their Uses. Dorling Kindersley, London, UK.

4. Choudhary M.I., Ali S., Thadhani V.M. \& Karunaratne V. (2009). Natural Novel Antioxidants, Patent Application Number: 11/838567, Publication Date 02/19/2009.

5. Dhanabalasingham B., Karunaratne V., Gunatilaka A.A.L., Tezuka Y. \& Kikuchi T. (1996). Biogenetically important quinonemethides and other constituents of Salacia reticulata. Phytochemistry 42: 1377 - 1385.

6. Elya B., Basah K., Mun'im A., Yuliastuti W., Bangun A. \& Septiana E.K. (2012). Screening of $\alpha$-glucosidase inhibitory activity from some plants of apocynaceae, clusiaceae, euphorbiaceae, and rubiaceae. Journal of Biomedicine and Biotechnology 2012: 281078.

7. Gunatilaka A.A.L., Dhanabalasingham B., Karunaratne V., Kikuchi T. \& Tezuka Y. (1993). Studies on terpenoids and steroids. part 27. structure of a D:A-friedooleanane triterpenoid from Salacia reticulate and revision of the structure of kokoonol, kokzeylanol series of triterpenoids. Tetrahedron 45: 10397 - 10404.

8. Huneck S. (1999). The significance of lichens and their metabolites. Naturwissenschaften 86(12): $559-570$. DOI: http://dx.doi.org/10.1007/s001140050676

9. Huneck S. \& Yoshimura I. (1996). Identification of Lichen Substances. Springer, Berlin, Germany.

DOI: http://dx.doi.org/10.1007/978-3-642-85243-5

10. Jayalal R.G.U., Wolseley P.A., Gueidan C., Aptroot A., Wijesundara D.S.A. \& Karunaratne V. (2012). Anzia mahaeliyensis and Anzia flavotenuis, two new species from Sri Lanka. The Lichenologist 44 (3): 381 - 389.

DOI: http://dx.doi.org/10.1017/S0024282911000946

11. Katulanda P., Constantine G.R., Mahesh J.G., Sheriff R., Seneviratne R.D. \& Wijeratne S. (2008). Prevalence and projections of diabetes and pre-diabetes in adults in Sri Lanka - Sri Lanka diabetes, cardiovascular study (SLDCS). Diabetes Medicine 25 (9): 1062 - 1069.

DOI: http://dx.doi.org/10.1111/j.1464-5491.2008.02523.x

12. Karunaratne V., Bombuwela K., Kathirgamanathar S. \& Thadhani V.M. (2005). Lichens: a chemically important biota. Journal of the National Science Foundation of Sri Lanka 33 (3): 169 - 186.

13. Kumar S., Narwal S., Kumar V. \& Prakash O. (2011). $\alpha$ Glucosidase inhibitors from plants: a natural approach to treat diabetes. Pharmacognosy Review 5(9): $19-29$. DOI: http://dx.doi.org/10.4103/0973-7847.79096

14. Oki Y., Okubo M., Tanaka S., Nakanish K. \& Murase T. 
(2000). Diabetes mellitus secondary to glycogen storage disease type III. Diabetic Medicine 17: 810 - 812 . DOI: http://dx.doi.org/10.1046/j.1464-5491.2000.00378.x

15. Orange A., Wolseley P., Karunaratne V. \& Bombuwela K. (2001). Two leprarioid lichens new to Sri Lanka. Bibliotheca Lichenologica 78: 327 - 333.

16. Raskin P.R., Hollander P.A., Lewin A., Gabbay R.A., Bode B. \& Garber A.J. (2007). Basal insulin or premix analogue therapy in type 2 diabetes patients. European Journal of Internal Medicine 18: 56 - 62 .

DOI: http://dx.doi.org/10.1016/j.ejim.2006.09.006

17. Tezuka Y., Kikuchi T., Dhanabalasingham B., Karunaratne V. \& Gunatilaka A.A.L. (1993). Salacenonal: a novel nortriterpenoid aldehyde of biogenetic significance from Salacia reticulata. Natural Product Letters 3(4): 273 - 276. DOI: http://dx.doi.org/10.1080/10575639308043876

18. Tezuka Y., Kikuchi T., Dhanabalasingham B., Karunaratne V. \& Gunatilaka A. A. L. (1994). Studies on terpenoids and steroids, part 25. Complete ${ }^{1} \mathrm{H}$ and ${ }^{13} \mathrm{C}$ NMR assignments of salaciquinone, a new 7-oxo-quinonemethide dinortriterpenoid from Salacia reticulata. Journal of Natural Products 57(2): $270-276$.

DOI: http://dx.doi.org/10.1021/np50104a012

19. Thadhani V.M., Choudhary M.I., Ali S., Omar I., Siddique H. \& Karunaratne V. (2011a). Antioxidant activity of some lichen metabolites. Natural Products Research 25(19): $1827-1837$.

DOI: http://dx.doi.org/10.1080/14786419.2010.529546
20. Thadhani V.M., Khan S.N., Karunaratne V. \& Choudhary M.I. (2011b). $\alpha$-Glucosidase inhibitors from lichens, United States Patent 7867989, Application number: 11/767465, Publication Date 01/11/2011

21. Thadhani V.M., Choudhary M.I., Khan S. \& Karunaratne V. (2012). Antimicrobial and toxicological activities of some depsides and depsidones. Journal of the National Science Foundation of Sri Lanka 40 (1): 43 - 48.

DOI: http://dx.doi.org/10.4038/jnsfsr.v40i1.4167

22. Tundis R., Loizzo M.R. \& Menichini F. (2010). Natural products as alpha-amylase and alpha-glucosidase inhibitors and their hypoglycaemic potential in the treatment of diabetes: an update. Mini Review in Medicinal Chemistry 10(4): $315-331$.

DOI: http://dx.doi.org/10.2174/138955710791331007

23. Williams D.E., Whitney L., Togias J., Singh M., McDonald L., Kathirgamanathar S., Karunaratne V. \& Andersen R.J. (2011). Depsidones Isolated from the Sri Lankan Lichen Parmotrema sp. exhibit selective PLK1 inhibitory activity. Pharmaceutical Biology 49(3): 296 - 301.

DOI: http://dx.doi.org/10.3109/13880209.2010.517540

24. Yoshikawa M., Murakami T., Shimada H., Matsuda H., Yamahara J., Tanabe G. \& Muraoka O. (1997). Salacinol, potent antidiabetic principle with unique thiosugarsulfonium sulfate structure from the ayurvedic traditional medicine Salacia reticulata in Sri Lanka and India. Tetrahedron Letters 38 (48): $8367-8370$. 